\title{
Utilization of Bitter orange seeds as a novel source for recovery of pectin: Compositional and rheological characterization
}

\section{Mohammad Nejatian}

Kermanshah University of Medical Sciences

Diako Khodaei ( $\nabla$ diako.khodaei@hotmail.com )

Tarbiat Modares University

Hassan Ahmadi Gavlighi

Tarbiat Modares University

Azizollaah Zargaraan

National Nutrition and Food, Shahid Beheshti University

\section{Research Article}

Keywords: Pectin, Orange seeds, Sugar composition, Molecular weight, Rheological properties

Posted Date: December 27th, 2021

DOI: https://doi.org/10.21203/rs.3.rs-651981/v2

License: (c) (i) This work is licensed under a Creative Commons Attribution 4.0 International License. Read Full License 


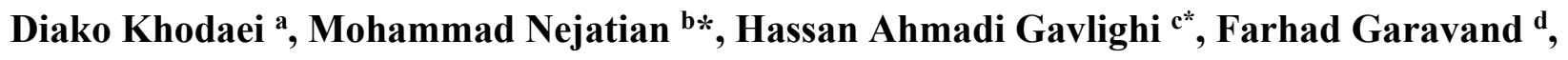

\section{Ilaria Cacciotti ${ }^{\text {e }}$}

6

${ }^{a}$ School of Science and Computing, Galway-Mayo Institute of Technology (GMIT), Galway H91 T8NW, Ireland

${ }^{\mathrm{b}}$ Department of Nutrition Science and Food Hygiene, Faculty of Health, Baqiyatallah University of Medical Sciences, Tehran, Iran

d Department of Food Chemistry and Technology, Teagasc Moorepark Food Research Centre, 


\section{Abstract}

22 The seeds from bitter orange, a by-product from the juice making step, hold the potential to

23 facilitate novel, easy yet high quality pectin extraction. To test this hypothesis, the pectin from

24 orange seeds (OSP) were extracted by distilled water and its compositional parameters and

25 rheological behavior then evaluated. Results showed that galacturonic acid was the major 26 component of OSP ( $\sim 225 \mathrm{mg} / \mathrm{g})$ confirming the purity of extracted pectin, followed by glucose

27 and some minor neutral sugars. $\mathrm{M}_{\mathrm{w}}, \mathrm{R}_{\mathrm{n}}$ and, $\mathrm{R}_{\mathrm{z}}$ for the OSP were $4511.8(\mathrm{kDa}), 61(\mathrm{~nm})$, and 61.1

28 (nm), respectively. Rheological measurements showed shear-thinning behavior for OSP that by 29 increasing temperature from 5 to $45{ }^{\circ} \mathrm{C}$, the viscosity of the gum decreased. Power law fitted as 30 the best rheological model describing the flow behavior of OSP. Strain sweep dynamic rheological 31 measurements confirmed an entangled network structure for OSP and the addition of $\mathrm{NaCl}$ to the 32 gum dispersion, decreased the consistency coefficient from 35.6 to 23.18 Pa.s $\mathrm{s}^{\mathrm{n}}$, while the flow 33 behavior index remained unchanged. These results demonstrate for the first time that the OSP can 34 be used as a new source of pectin, with likely a wide range of applications in food industry.

36 Keywords: Pectin; Orange seeds; Sugar composition; Molecular weight; Rheological properties. 


\section{Introduction}

Hydrocolloids are water-soluble biopolymers with a wide application in food industry. They are commonly used to improve textural properties of food as a gelation and viscosity improving agents (Nejatian et al., 2020). Pectin one of the major hydrocolloids in food processing industry is a polysaccharide with 1, 4-galacturonic acid units and some of its carboxyl groups can be substituted with methyl esters or amide groups (Löfgren and Hermansson, 2007). It is widely used as an ingredient for providing specific textural and rheological properties to processed food as a gelling/thickening agent or as an emulsion stabilizer for acidified dairy drinks (Christiaens et al., 2016).

The source of pectin, the extraction procedures, the particle size distribution, the patterns of acylation, the degree of esterification (DE) and the nature and position of the neutral sugars have a great impact on the specifications of pectin from the various origins (Maxwell et al., 2012). Pectin is considered as an invaluable by-product of the citrus processing industry. About $85 \%$ of the globally commercial pectin is sourced from citrus waste which can be produced from fresh or processed peels of lemon, grapefruit, and oranges (Berk, 2016).

Disadvantages associated with pectin extraction from citrus peels include the use of corrosion mineral acid, high temperature and extended extraction time. Together these may affect pectin quality and moreover damage equipment. Furthermore, the steps of filtration, discoloration and concentration of pectin solution before alcohol precipitation are associated with both high cost and use of time (May, 1990). Therefore, new sources of pectin with both lower extraction time and production costs is both economically and technologically appealing (Shan, 2016). Previous studies examining pectin extraction have been varied in their approach. The extraction and physiochemical properties of pectin from the heads of sunflowers was studied by Peng et al. (Peng 
et al., 2020). Asgari and co-workers (Asgari et al., 2020) studied the walnut processing waste as a

61 novel source of pectin. Gharibzahedi et al. (Gharibzahedi et al., 2019) evaluated the pectin

62 extracted from Fig (Ficus carica L.) skin. Chaliha and co-authors (Chaliha et al., 2018) extracted

63 pectin from Terminalia ferdinandiana- a native Australian fruit. Finally, the possibility of using

64 Palmyra Palm (Borassus aethiopum Mart.) fruit was evaluated by Assoi et al. (Assoi et al., 2017).

65 The bitter orange (Citrus aurantium) contains many seeds and differs from the orange by several

66 characters including the acidic pulp and bitterer albedo (Moufida and Marzouk, 2003). It is

67 commonly used for essential oils, in the perfume industry and for the production the marmalade.

68 In the Middle East, the juice of the ripen fruit can be used as a salad dressing or as a flavoring

69 (Zibaee et al., 2020).

70 It is necessary to understand the rheological properties and determination of sugar composition of

71 pectin from new sources to evaluate their thickener potential. The flow behavior of hydrocolloids

72 solutions is important to assess processing parameters, textural properties of formulated foods,

73 design of unit operations and development of product engineering (Balaghi et al., 2011; Rincón et

74 al., 2014). To date there is no report on the extraction of pectin from orange seeds and hence an

75 evaluation of its compositional and functional properties. Therefore, the main objective of this

76 research was to extract and characterize the sugar composition, molecular weight, and rheological

77 properties of pectin from bitter orange seeds as a novel source of pectin.

78

2. Material and methods

80

2.1 Materials and extraction method 
81 The bitter orange fruit (Citrus aurantium L.) was used in this study, collected from trees growing

82 in Mazandaran province of Iran during October and November 2020 and according to the

83 permission and the national guideline of Agricultural Research Education and Extension

84 Organization of Iran. Phenotypic identification of the specimen was done by Dr. Saeid Hazrati, 85 academic member of Shahid Madani University of Tabriz, Iran.

86 The seeds were collected from bitter oranges during the juice extraction. Seeds were washed with

87 tap water to remove the fruit pulp and drained completely to remove the excess water. Afterward,

88 the seeds soaked in distilled water $(\mathrm{pH}=7)$ in a seed ratio of $6: 1$ at $70 \pm 1{ }^{\circ} \mathrm{C}$ and stirred for $30 \mathrm{~min}$

89 (solid/liquid ratio selected based on preliminary test). Thereafter, pectin coats were removed from

90 the seeds by passing through a $600 \mu \mathrm{m}$ sieve and collected in a flask. The extracted solution mixed

91 with three volumes of $96 \% \mathrm{v} / \mathrm{v}$ ethanol and placed in the fridge $\left(4^{\circ} \mathrm{C}\right)$. After $24 \mathrm{~h}$, the flocculated

92 pectin collected and dried in an oven with circulating air at $30{ }^{\circ} \mathrm{C}$. The dehydrated pectin (OSP)

93 was pulverized with a miller, packed, and kept in cool and dry condition prior test.

94 Standards of monosaccharides (galacturonic acid, glucose, arabinose, galactose, rhamnose, and 95 fucose) and trifluoracetic acid (TFA) with purity of $\geq 99 \%$ were purchased from Merck 96 (Darmstadt, Germany).

98 AOAC method (AOAC, 2016) was used for determination of moisture content and total ash 99 content. Kjeldal method was used for the determination of total protein content with the nitrogen 100 value of 6.25 (Razavi et al., 2014).

101 After hydrolysis $4 \mathrm{~g} / \mathrm{l}$ of OSP by TFA (2 M) for $2 \mathrm{~h}$ at $121{ }^{\circ} \mathrm{C}$, the monosaccharide composition 102 analyzed by high-performance anion-exchange chromatography with a pulsed amperometric 
103 detector (DECADE Elite). Separations carried out in a CarboPac PA1(4×250mm) column (Dionex

104 Corp., Sunnyvale, CA). Samples were passed through $0.22 \mu \mathrm{m}$ filter prior injections into the 105 column. The monosaccharides separation through the column was carried out according to the 106 method of (Gavlighi et al., 2013).

\subsection{Degree of esterification (DE)}

108

109

110

111

112

113

114

115

116 117 following equation (Hosseini et al., 2016):

118

\subsection{Determination of molecular parameters}

The titration method proposed by Chaharbaghi et al. (Chaharbaghi et al., 2017) was used for determination of DE of pectin sample. To do this, $100 \mathrm{mg}$ of dried powder of sample was added to $2 \mathrm{ml}$ of ethanol and dissolved in $20 \mathrm{ml}$ deionized water at $40{ }^{\circ} \mathrm{C}$. Afterward, $5 \mathrm{ml}$ of phenolphthalein reagent was added to the solution and titrated with $\mathrm{NaOH}(0.1 \mathrm{M})$. The amount of $\mathrm{NaOH}$ used for titration recorded as $\mathrm{V}_{\mathrm{i}}$. Afterward, $10 \mathrm{ml}$ of $\mathrm{NaOH}$ was added to the solution and mixed for $30 \mathrm{~min}$ for complete hydrolysis. $10 \mathrm{ml}$ of $\mathrm{HCl}(0.1 \mathrm{M})$ was introduced to the solution and mixed vigorously to completely disappear the pink color. After the addition of drops of phenolphthalein, the excessive amount of $\mathrm{HCl}$ was titrated with $\mathrm{NaOH}$ to obtain a pale pink color and the volume of $\mathrm{NaOH}$ was recorded as the $\mathrm{V}_{\mathrm{f}}$. The $\mathrm{DE}$ of pectin was calculated according the

$$
D E=\left(V_{f} / V_{i}+V_{f}\right) \times 100
$$

Molecular weight averages $\left(\mathrm{M}_{\mathrm{n}}, \mathrm{M}_{\mathrm{w}}, \mathrm{M}_{\mathrm{z}}\right)$ of the OSP were determined by using a size exclusion chromatography system (flow rate of $0.4 \mathrm{~mL} / \mathrm{min}$ with $0.15 \mathrm{M} \mathrm{NaNO}_{3}$ and $0.02 \% \mathrm{NaN}_{3}$ ) and equipped with TSK G5000 PW column $(7.5 \times 600$ mm; Toso Biosep, Montgomeryville, PA, USA) joint to a UV detector (Waters, 2487), multi-angle laser light scattering (HELEOS; Wyatt Technology Corp, Santa Barbara, CA, USA) and a refractive index detector (Waters, 2414) 
125 (HPSEC-UV-MALLS-RI). Bovine serum albumin (BSA) was used as a standard for determination

126 of the volume delays among the US, MALLS, and RI detectors. ASTRA 5.3 software (Wyatt

127 Technology Corp.) applied for data acquisition and to calculate the $\mathrm{M}_{\mathrm{w}}$ average, $\mathrm{M}_{\mathrm{n}}$, and $\mathrm{M}_{\mathrm{z}}$.

129 In order to determine the rheological characteristics of gum, OSP dispersions at concentrations $1300.1,0.3,0.5,0.7$ and $1 \%(\mathrm{w} / \mathrm{v})$ were first prepared by dissolving of the required amount of dry 131 powdered gum in distilled water and gently stirred at room temperature for $2 \mathrm{~h}$. The gum 132 dispersions were stored overnight at $5{ }^{\circ} \mathrm{C}$ to assure that the hydration of the polysaccharide was 133 complete.

134 Both steady shear viscosity and oscillatory shear tests were performed by Physica MCR 301 135 rheometer (Anton Paar GmbH, Graz, Austria) so that a concentric cylinder geometry (radius ratio 136 of 1.035) and a parallel plate geometry (25-mm diameter; 0.5-mm gap) were used for dilute 137 samples and concentrated dispersions, respectively. The temperature was adjusted to $25^{\circ} \mathrm{C}$ with a 138 Viscotherm VT2 circulating bath and a controlled Peltier system (Anton Paar, GmbH) with an 139 accuracy of $\pm 0.01{ }^{\circ} \mathrm{C}$.

140 Shear sweeps were conducted at $25^{\circ} \mathrm{C}$ between 0.001 to $1000 \mathrm{~s}^{-1}$ so as to obtain flow curves. Flow 141 behavior of the dispersions were assessed by fitting the shear rate versus shear stress values to five 142 usual models, i.e., Newtonian $(\tau=m \dot{\gamma})$, Power-law $\left(\tau=m \dot{\gamma}^{\mathrm{n}}\right)$, Herschel-Bulkley $\left(\tau=m \dot{\gamma}^{\mathrm{n}}+\tau_{0}\right)$, 143 Bingham $\left(\tau=\mathrm{m} \dot{\gamma}+\tau_{0}\right)$, and Casson $\left(\sqrt{\tau}=\mathrm{m} \sqrt{\dot{\gamma}}+\sqrt{\tau_{0}}\right)$, Where $\tau$ is the shear stress (Pa), $m$ is the 144 consistency coefficient (Pa.sn), $\dot{\gamma}$ is the shear rate $\left(1 \mathrm{~s}^{-1}\right)$, the exponent $\mathrm{n}$ is flow behavior index 145 (dimensionless) and $\tau_{0}$ is the yield stress (Pa) (Nejatian and Abbasi, 2019; Nejatian et al., 2018). 
146 The effect of temperature on the flow properties was measured by performing shear sweeps for 1

$147 \%(\mathrm{w} / \mathrm{v})$ OSP dispersion at $5^{\circ} \mathrm{C}, 25^{\circ} \mathrm{C}$ and $45^{\circ} \mathrm{C}$. Also, the temperature dependency of apparent

148 viscosity was evaluated by fitting the Arrhenius model $\left(\eta=\eta \circ \exp ^{\frac{E_{a}}{R T}}\right)$ in which $\eta_{0}$ is the pre149 exponential factor (Pa.), $E_{a}$ the activation energy for viscous flow $(\mathrm{J} / \mathrm{mol}), R$ the universal gas 150 constant $(8.314 \mathrm{~J} / \mathrm{mol} \mathrm{K})$, and $T$ the absolute temperature $(\mathrm{K})$.

151 The $1 \%(\mathrm{w} / \mathrm{v})$ OSP gum dispersion was prepared for oscillatory shear measurements. Strain sweep 152 test was performed over the range $0.05-100 \%$ at a fixed frequency $(1 \mathrm{~Hz})$ to determine the linear 153 viscoelastic region (LVR). Frequency sweep tests were also carried out at a wide range of 154 frequencies $(0.01-20 \mathrm{~Hz})$ and a constant strain $(<\mathrm{LVR}, \sim 0.5 \%)$ to evaluate the dynamic 155 rheological properties $\left(\mathrm{G}^{\prime}\right.$ and $\left.G^{\prime \prime}\right)$.

156 In addition, the rheological behavior in response to the salt concentration $(0.2 \mathrm{M})$ and type $(\mathrm{NaCl}$ 157 and $\left.\mathrm{CaCl}_{2}\right)$ were determined just at a certain gum concentration, $1 \%(\mathrm{w} / \mathrm{v})$ and temperature, 25 $158{ }^{\circ} \mathrm{C}$.

160 All the measurements were made in triplicate and data were presented as mean \pm standard 161 deviation. Microsoft Excel Software (Microsoft Office, Package 2012) used for plotting the 162 rheological curves.

\section{Results and discussions}

\subsection{Compositional analysis}

165 The physicochemical and molecular parameters of the OSP are presented in Table 1. The results 166 showed the OSP contained $9.17 \%$ moisture, $1.88 \%$ ash, $2.14 \%$ of protein, $86.8 \%$ of total 
167 carbohydrates, and DE of $79.68 \%$. Plant's variety and growing conditions, extraction and 168 purification process are important factors affecting the chemical composition of hydrocolloids 169 (Razavi et al., 2014). Similar chemical composition for pectin extracted from sour oranges and the 170 total ash, moisture content, and protein content were 1.89, 8.81, and 1.45, respectively (Hosseini 171 et al., 2019).

172 Monosaccharides analysis using liquid chromatography (HPLC) showed that galacturonic acid 173 was the major component in OSP ( $425 \mathrm{mg} / \mathrm{g}$, about $85 \%$ of sugar composition). This was 174 followed by glucose (54 mg/g, about $10 \%$ of sugar composition). The wide diversity of 175 composition by acid and glucose indicates that OSP has rich pectin content but also some cellulose 176 or starch-like glucans. Such sugar composition was previously observed in the commercial low 177 methoxyl pectin (Peng et al., 2020) and some pectin from different food waste streams (Müller178 Maatsch et al., 2016). Also, minor quantities of fucose, galactose, arabinose, and rhamnose (about $1794 \%$ of sugar composition) were also identified which can explain the complex polysaccharide 180 composition of OSP (Razavi et al., 2014). It has been reported that galactose, rhamnose, arabinose, 181 xylose and fucose are the principal neutral sugars found in pectin side chains (Hosseini et al., 182 2019). Hydrocolloids with a higher amount of fucose, xylose, galacturonic acid, methoxyl groups, 183 and lower amounts of arabinose and nitrogenous fractions are reported to exhibit high viscosity 184 (Anderson and Grant, 1988). Similar observations were also reported by Balaghi et al. (2011) and 185 showed that tragacanth gums with a greater quantity of galacturonic acid and fucose exhibited 186 higher consistency coefficients (Balaghi et al., 2011). Similarly, Hosseini et al. (2019) observed 187 that galacturonic acid (65.3\%) was the main monosaccharide of pectin extracted from sour orange 188 peels (Hosseini et al., 2019). 
190 The results of molecular weights parameters are presented in Table $1 . \mathrm{M}_{\mathrm{w}}$ (weight-average molar 191 mass), $R_{n}$ (number average molar mass) and, $R_{z}$ (z-average molar mass) for the OSP were 4511.8 $192(\mathrm{kDa}), 61(\mathrm{~nm})$, and $61.1(\mathrm{~nm})$, respectively. The $\mathrm{M}_{\mathrm{w}}$ measurement indicates a large $\mathrm{M}_{\mathrm{w}}$ for OSP 193 confirming that such polysaccharides have a tendency to exhibit a higher viscous and pseudoplastic 194 properties when dissolved in water (Hosseini-Parvar et al., 2010). The high molecular weight of 195 OSP is similar to other hydrocolloids such as xanthan $(4200 \mathrm{kDa})$, locust bean gum $(50-3000 \mathrm{kDa})$, 196 Basil seed gum (1045-5980 kDa), guar (50-8000 kDa), psyhyllium (1500 kDa), and Karaya 197 (10,000 kDa) (Faria et al., 2011; Harding et al., 2017; Imeson, 2011; Milani and Maleki, 2012; 198 Naji-Tabasi et al., 2016). Different studies have shown that the $\mathrm{pH}$ of extraction may have an effect on the molecular weight of pectin and pectin extracted in higher $\mathrm{pH}$ shows the higher $\mathrm{M}_{\mathrm{w}}$ due to 200 the higher DE value of the pectin (Cho et al., 2019; Yapo et al., 2007). Using distilled water $(\mathrm{pH}=7)$ to extract pectin from OSP, may explain the high $\mathrm{M}_{\mathrm{w}}$ observed for the extracted pectin in this

202 research. Gavlighi and co-workers (2018) reported that the $\mathrm{M}_{\mathrm{w}}$ of pectin extracted from 203 pomegranate peels depended on the extraction condition and the highest $M_{w}$ and $R_{g}$ observed for 204 the buffer extracted pectin $\left(18,631.85 \times 10^{3} \mathrm{~g} / \mathrm{mol}\right.$ and $\left.102.80 \mathrm{~nm}\right)$ (Gavlighi et al., 2018).

\subsection{Rheological properties}

Figure 1a compares the flow behavior of OSP dispersions within a concentration range of 0.1-1 $\mathrm{wt} \%$. On the basis of the highest determination coefficient $\left(R^{2}\right)$ and the lowest root mean standard error (RMSE), the flow behavior of all dispersions of OSP with different concentrations were

210 particularly nonlinear and best fitted to Power-law model $\left(\tau=m \dot{\gamma}^{n}\right)$. The coefficients of evaluated

211 rheological models are shown in Table 2. The power law model has a wide application in food 
212 industry and many studies have proved this model as the most appropriate model for flow behavior

213 study of the majority of food hydrocolloids (Khodaei et al., 2014).

214 The dependency of the apparent viscosity on the shear rate for the OSP dispersions in various 215 concentrations is shown in Figure 1b. As evident, the OSP dispersions indicated the typical 216 viscosity vs shear rate relationship of a colloidal food system including the polysaccharides 217 solutions. At lower shear rate $(\sim 0.11 / \mathrm{s})$ and especially at higher gum concentrations $(0.5-1 \mathrm{wt} \%)$, 218 the apparent viscosity was nearly independent of the shear rate. Indeed, when the shear rate is low, 219 the Brownian motion dominates the structural forces and favors the alignment of the elongated 220 coil along the flow direction. However, the viscosity reduced with increasing shear rate (shear 221 thinning behavior) arose from the equilibrium between the hydrodynamic forces and the structural 222 forces (Barnes, 2000; Windhab, 1995). In fact, above a critical shear rate, the deformation rate of 223 the gum chain entanglement due to the application of external forces becomes greater than the 224 formation rate of the new entanglement (Lapasin and Pricl, 1995).

225 As seen (Fig. 1b), the apparent viscosity decreased with reducing the gum concentration to $0.1 \%$, 226 throughout the shear rate study. In addition, as the concentration of dispersion increases, the 227 intermolecular interactions increase and improve the viscosity. The positive effect of gum 228 concentration on the apparent viscosity can be also followed in Power law model parameters 229 (Table 1), so that with increasing in OSP concentration, the consistency coefficient $(k)$ and flow 230 behavior index $(n)$ increased and decreased, respectively. Generally, it seems that the apparent 231 viscosity of OSP is similar or even better than that of some other polysaccharides such as some 232 species of gum tragacanth (Balaghi et al., 2010), pectin (Marcotte et al., 2001), Persian gum 233 (Fadavi et al., 2014), guar gum (Kayacier and Dogan, 2006), carboxymethyl cellulose (Yasar et 234 al., 2007), etc. 
235 Strain sweep dynamic rheological measurements showed that for OSP dispersion (1wt\%) storage 236 modulus $\left(\mathrm{G}^{\prime}\right)$ was somewhat higher than loss modulus $\left(\mathrm{G}^{\prime \prime}\right)$ (Fig. 2a). Nevertheless, the superiority 237 of each of these modules over the other in the frequency sweep test depended on the frequency. 238 As is evident in Fig. 2b, there was the transition from a predominantly viscous response at longer 239 time scales $\left(\mathrm{G}^{\prime \prime}>\mathrm{G}^{\prime}\right)$ to a predominantly elastic response at shorter time scales $\left(\mathrm{G}^{\prime}>\mathrm{G}^{\prime \prime}\right)$, indicating 240 the dispersion has an entangled network structure. Such rheological behavior can be compared to 241 some gum tragacanth species (Astragalus parrowianus and fluccosus) (Balaghi et al., 2011) and 242 deacetylated Sterculia striata polysaccharide (De Brito et al., 2005).

\subsubsection{Effect of salt and temperature on rheological properties}

244 The Addition of salt $(\mathrm{NaCl})$ to the OSP dispersion $(1 \mathrm{wt} \%)$ decreased the apparent viscosity with 245 no changes in the reduction pattern or flow behavior (Fig. 3a). Moreover, the consistency 246 coefficient of $1 \mathrm{wt} \%$ OSP aqueous dispersion in the presence of $0.2 \mathrm{M} \mathrm{NaCl}$ decreased from 35.60

247 to $23.18 \mathrm{~Pa}_{\mathrm{s}} \mathrm{n}^{\mathrm{n}}$ while the flow behavior index remained almost unchanged (0.22 against 0.25$)$. This 248 effect can be assigned to charge screening effect of the salt on long-range electrostatic repulsion 249 among the uronic acid residues of OSP (Balaghi et al., 2010). Based on strain sweep test, the salt 250 addition reduced amount of both $G^{\prime}$ and $G^{\prime \prime}$, but the $G^{\prime}$ values in LVR were still greater than $G^{\prime \prime}$ 251 (Fig. 2a). On the contrary to the NaCl-free OSP dispersion, the dispersion containing $\mathrm{NaCl}(0.2$ 252 M) indicated a crossover point at a high frequency (Fig. 2b). Furthermore, in the presence of $\mathrm{NaCl}$, 253 the $\mathrm{G}^{\prime}$ and $\mathrm{G}^{\prime \prime}$ gap was larger. This suggests that $\mathrm{NaCl}$ caused a more drastic decrease in elastic 254 component than the viscous component. Interestingly, as is evident (Fig. 3a), incorporation of $255 \mathrm{CaCl}_{2}$ to OSP dispersion increased the viscosity which can be related to the bridging effect of $\mathrm{Ca}^{2+}$ 256 forming a strong gel network of polysaccharide chains. 
257 Figure $3 \mathrm{~b}$ shows the temperature influence on the apparent viscosity of $1 \mathrm{wt} \%$ OSP dispersion as

258 a function of shear rate. As seen, the viscosity significantly declined by increasing in temperature

259 from 5 to $45{ }^{\circ} \mathrm{C}$. This effect can be also observed in Power law model parameters so that by

260 increasing the temperature, the consistency coefficient decreased and the flow behavior index

261 increased (Table 3). However, the flow behavior index of the dispersion is still far from the typical

262 value of a Newtonian fluid (i.e., $\mathrm{n}=1$ ). In addition, the shear rate had a considerable effect on the

263 temperature dependence of OSP dispersion viscosity. Figure 3c shows the value of activation

264 energy obtained at two shear rates, 0.1 and $101 / \mathrm{s}$ for $1 \mathrm{wt} \%$ OSP aqueous dispersions. High $R^{2}$

265 values suggested that the apparent viscosity of dispersion in relation to temperature follows the

266 Arrhenius model. A higher flow $E_{a}$ value at low rates of shear implicates more sensitivity of OSP

267 viscosity to temperature changes. This trend was also reported for other hydrocolloids such as

268 pectin (da Silva et al., 1994).

\section{Conclusion}

271 The compositional and rheological behavior of pectin extracted from bitter orange seeds (OSP) as

272 a novel source of high-quality pectin was evaluated in this study. Monosaccharides compositions

273 revealed that galacturonic acid was the major structure of pectin followed by glucose. Arabinose,

274 galactose, rhamnose, and fucose were also observed in smaller amounts and confirm the side chain

275 structure of the pectin. Molecular weight analysis of the pectin showed a high $\mathrm{M}_{\mathrm{w}}$ of $4512 \mathrm{kDa}$.

276 OSP dispersions exhibited a non-Newtonian shear thinning behavior. Strain sweep dynamic

277 rheological measurements exhibited a higher storage modulus $\left(\mathrm{G}^{\prime}\right)$ than loss modulus $\left(\mathrm{G}^{\prime \prime}\right)$ and it

278 confirms the entangled structure of OSP. In conclusion, the mucilage extracted from orange seeds 
279 is rich in pectin and demonstrates potential use as gelling or emulsion stabilizer in food 280 applications. Further studies to evaluate the functional properties and characterization of this novel 281 source of pectin is needed but if fully elucidated could potentially revolutionize the use of pectin 282 in the food industry.

283 Conflict of interest

284 All the authors declare no conflict of interest.

285 Funding

286 This research did not receive any specific grant from funding agencies in the public, commercial, or 287 not-for-profit sectors.

288 Acknowledgement

289 The authors would like to thank Dr. Edel McGarry for offering help in proofreading and language 290 editing of the manuscript.

\section{References}

292 Anderson, D., Grant, D. The chemical characterization of some Astragalus gum exudates. Food 293 Hydrocoll. 2, 417-423 (1998)

294 AOAC, G. Official methods of analysis of AOAC International. Rockville, MD: AOAC 295 International, ISBN: 978-0-935584-87-5 (2016)

296 Asgari, K., Labbafi, M., Khodaiyan, F., Kazemi, M., Hosseini, S.S. Valorization of walnut 297 processing waste as a novel resource: Production and characterization of pectin. J. Food Process. 298 Pres. 44, e14941 (2020)

299 Assoi, S., Konan, K., Agbo, G.N., Dodo, H., Holser, R., Wicker, L. Palmyra palm (Borassus 300 aethiopum Mart.) fruits: novel raw materials for the pectin industry. J. Sci. Food Agric. 97, 2057$3012067(2017)$ 
Balaghi, S., Mohammadifar, M.A., Zargaraan, A. Physicochemical and rheological characterization of gum tragacanth exudates from six species of Iranian Astragalus. Food Biophys. 5, 59-71 (2010)

Balaghi, S., Mohammadifar, M.A., Zargaraan, A., Gavlighi, H.A., Mohammadi, M. Compositional analysis and rheological characterization of gum tragacanth exudates from six species of Iranian Astragalus. Food Hydrocoll. 25, 1775-1784 (2011)

Barnes, H.A. A handbook of elementary rheology. University of Wales, Institute of NonNewtonian Fluid Mechanics (2000)

Berk, Z. Citrus fruit processing. Academic press (2016)

Chaharbaghi, E., Khodaiyan, F., Hosseini, S.S. Optimization of pectin extraction from pistachio green hull as a new source. Carbohydr. Polym. 173, 107-113 (2017)

Chaliha, M., Williams, D., Smyth, H., Sultanbawa, Y. Extraction and characterization of a novel Terminalia pectin. Food Sci. Biotechnol. 27, 65-71 (2018)

Cho, E.-H., Jung, H.-T., Lee, B.-H., Kim, H.-S., Rhee, J.-K., Yoo, S.-H. Green process development for apple-peel pectin production by organic acid extraction. Carbohydr. Polym. 204, 97-103 (2019)

Christiaens, S., Van Buggenhout, S., Houben, K., Jamsazzadeh Kermani, Z., Moelants, K.R., Ngouemazong, E.D., Van Loey, A., Hendrickx, M.E. Process-structure-function relations of pectin in food. Crit. Rev. Food Sci. Nutr. 56, 1021-1042 (2016)

da Silva, J.L., Gonçalves, M., Rao, M. Influence of temperature on the dynamic and steady-shear rheology of pectin dispersions. Carbohydr. Polym. 23, 77-87 (1994)

De Brito, A.C.F., Sierakowski, M.R., Reicher, F., Feitosa, J.P., De Paula, R.C.M. Dynamic rheological study of Sterculia striata and karaya polysaccharides in aqueous solution. Food Hydrocoll. 19, 861-867 (2005)

Fadavi, G., Mohammadifar, M.A., Zargarran, A., Mortazavian, A.M., Komeili, R. Composition and physicochemical properties of Zedo gum exudates from Amygdalus scoparia. Carbohydrate polymers. 101, 1074-1080 (2014)

Faria, S., de Oliveira Petkowicz, C.L., De Morais, S.A.L., Terrones, M.G.H., De Resende, M.M., de Franca, F.P., Cardoso, V.L. Characterization of xanthan gum produced from sugar cane broth. Carbohydr. Polym. 86, 469-476 (2011)

Gavlighi, H.A., Meyer, A.S., Zaidel, D.N.A., Mohammadifar, M.A., Mikkelsen, J.D. Stabilization of emulsions by gum tragacanth (Astragalus spp.) correlates to the galacturonic acid content and methoxylation degree of the gum. Food Hydrocoll. 31, 5-14 (2013) 
Gavlighi, H.A., Tabarsa, M., You, S., Surayot, U., Ghaderi-Ghahfarokhi, M. Extraction, characterization and immunomodulatory property of pectic polysaccharide from pomegranate peels: Enzymatic vs conventional approach. Int. J. Biol. Macromol. 116, 698-706 (2018)

Gharibzahedi, S.M.T., Smith, B., Guo, Y. Ultrasound-microwave assisted extraction of pectin from fig (Ficus carica L.) skin: Optimization, characterization and bioactivity. Carbohydr. Polym. 222, 114992 (2019)

Harding, S.E., Tombs, M.P., Adams, G.G., Paulsen, B.S., Inngjerdingen, K.T., Barsett, H. An introduction to polysaccharide biotechnology. CRC Press (2017)

Hosseini-Parvar, S., Matia-Merino, L., Goh, K., Razavi, S.M.A., Mortazavi, S.A. Steady shear flow behavior of gum extracted from Ocimum basilicum L. seed: Effect of concentration and temperature. J. Food Eng. 101, 236-243 (2010)

Hosseini, S.S., Khodaiyan, F., Kazemi, M., Najari, Z. Optimization and characterization of pectin extracted from sour orange peel by ultrasound assisted method. Int. J. Biol. Macromol. 125, 621629 (2019)

Hosseini, S.S., Khodaiyan, F., Yarmand, M.S. Aqueous extraction of pectin from sour orange peel and its preliminary physicochemical properties. Int. J. Biol. Macromol. 82, 920-926 (2016)

Imeson, A. Food stabilisers, thickeners and gelling agents. John Wiley \& Sons (2011)

Kayacier, A., Dogan, M. Rheological properties of some gums-salep mixed solutions. J. Food Eng. 72, 261-265 (2006)

Khodaei, D., Razavi, S.M., Khodaparast, M.H. Functional properties of Balangu seed gum over multiple freeze-thaw cycles. Food Res. Int. 66, 58-68 (2014)

Lapasin, R., Pricl, S. Rheology of polysaccharide systems, in: Lapasin, R. (Ed.), Rheology of industrial polysaccharides: Theory and applications. Springer, pp. 250-494 (1005)

Löfgren, C., Hermansson, A.-M. Synergistic rheological behaviour of mixed HM/LM pectin gels. Food hydrocoll. 21, 480-486 (2007)

Marcotte, M., Taherian Hoshahili, A.R., Ramaswamy, H.S. Rheological properties of selected hydrocolloids as a function of concentration and temperature. Food Res. Int. 34, 695-703 (2001)

Maxwell, E.G., Belshaw, N.J., Waldron, K.W., Morris, V.J. Pectin-an emerging new bioactive food polysaccharide. Trends Food Sci. Technol. 24, 64-73 (2012)

May, C.D. Industrial pectins: sources, production and applications. Carbohydr. Polym. 12, 79-99 (1990)

Milani, J., Maleki, G. Hydrocolloids in food industry. In Valdez, B. (Ed.), Food industrial processes-Methods and equipment. 2, 2-37. IntechOpen, ISBN: 978-953-51-4352-9 (2012) 
Moufida, S.d., Marzouk, B. Biochemical characterization of blood orange, sweet orange, lemon, bergamot and bitter orange. Phytochemistry. 62, 1283-1289 (2003)

Müller-Maatsch, J., Bencivenni, M., Caligiani, A., Tedeschi, T., Bruggeman, G., Bosch, M., Petrusan, J., Van Droogenbroeck, B., Elst, K., Sforza, S. Pectin content and composition from different food waste streams. Food Chem. 201, 37-45 (2016)

Naji-Tabasi, S., Razavi, S.M.A., Mohebbi, M., Malaekeh-Nikouei, B. New studies on basil (Ocimum bacilicum L.) seed gum: Part I-Fractionation, physicochemical and surface activity characterization. Food Hydrocoll. 52, 350-358 (2016)

Nejatian, M., Abbasi, S. Formation of concentrated triglyceride nanoemulsions and nanogels: natural emulsifiers and high power ultrasound. RSC Adv. 9, 28330-28344 (2019)

Nejatian, M., Abbasi, S., Azarikia, F. Gum Tragacanth: Structure, characteristics and applications in foods. Int. J. Biol. Macromol. 160, 846-860 (2020)

Nejatian, M., Abbasi, S., Kadkhodaee, R. Ultrasonic-Assisted Fabrication of Concentrated Triglyceride Nanoemulsions and Nanogels. Langmuir, 34, 11433-11441 (2018)

Peng, X., Yang, G., Shi, Y., Zhou, Y., Zhang, M., Li, S. Box-Behnken design based statistical modeling for the extraction and physicochemical properties of pectin from sunflower heads and the comparison with commercial low-methoxyl pectin. Sci. Rep. 10, 3595 (2020)

Razavi, S.M.A., Cui, S.W., Guo, Q., Ding, H. Some physicochemical properties of sage (Salvia macrosiphon) seed gum. Food Hydrocoll. 35, 453-462 (2014)

Rincón, F., Muñoz, J., Ramírez, P., Galán, H., Alfaro, M.C. Physicochemical and rheological characterization of Prosopis juliflora seed gum aqueous dispersions. Food Hydrocoll. 35, 348-357 (2014)

Shan, Y. Comprehensive utilization of citrus by-products. Academic Press (2016)

Windhab, E. Rheology in food processing, in: Beckett, S.T. (Ed.), Physico-chemical aspects of food processing. Springer, pp. 80-116 (1995)

Yapo, B., Robert, C., Etienne, I., Wathelet, B., Paquot, M. Effect of extraction conditions on the yield, purity and surface properties of sugar beet pulp pectin extracts. Food chem. 100, 1356-1364 (2007)

Yasar, F., Togrul, H., Arslan, N. Flow properties of cellulose and carboxymethyl cellulose from orange peel. J. Food Eng. 81, 187-199 (2007)

Zibaee, E., Kamalian, S., Tajvar, M., Amiri, M.S., Ramezani, M., Moghadam, A.T., Emami, S.A., Sahebkar, A. Citrus species: A Review of Traditional Uses, Phytochemistry and Pharmacology. Curr. Pharm. Des. 26, 44-97 (2020) 
Figures
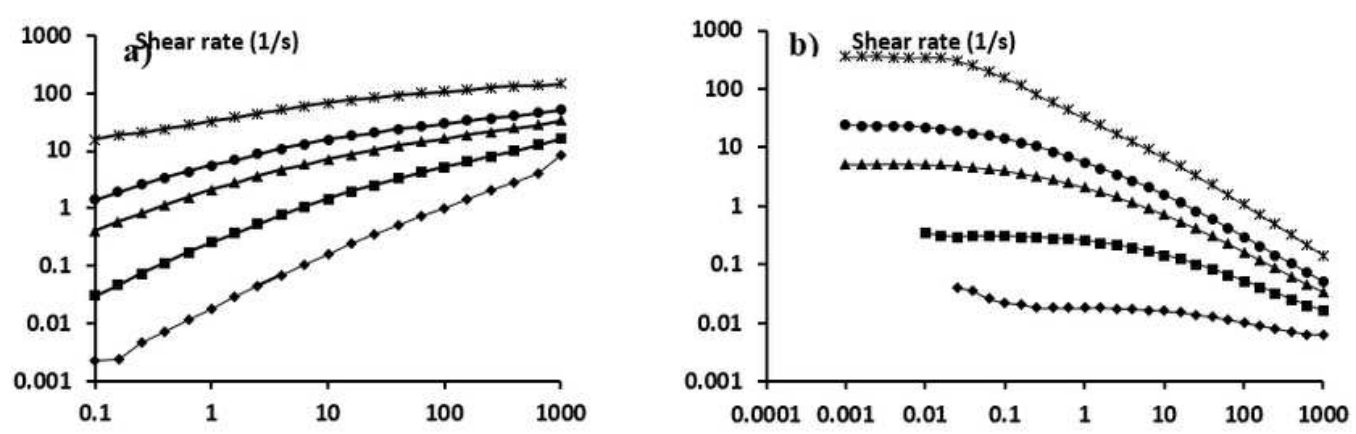

Figure 1. Comparison of the flow curves (a) and influence of shear rate on apparent viscosity of the OSP dispersions in different concentrations $[0.1 \mathrm{wt} \%(\bullet), 0.3 \mathrm{wt} \%(\bullet), 0.5 \mathrm{wt} \%(\bullet), 0.7 \mathrm{wt} \%(\bullet), 1 \mathrm{wt} \%(\boldsymbol{*})]$

\section{Figure 1}

See figure for legend.
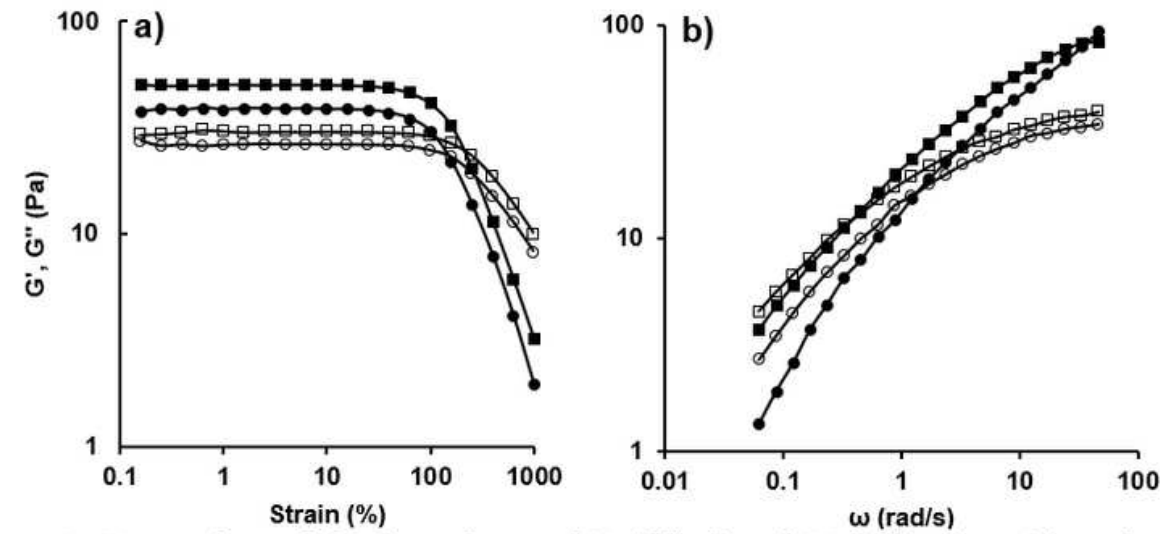

Figure 2. Comparison of the dependency of G' (filled) and G" (hollow) on (a) strain and (b) frequency for 1 wt\% OSP dispersions in the absence $(\square, \mathbf{\square})$ and presence $(\mathrm{O}, \bullet)$ of added $\mathrm{NaCl}(0.2 \mathrm{M})$.

\section{Figure 2}

See figure for legend. 

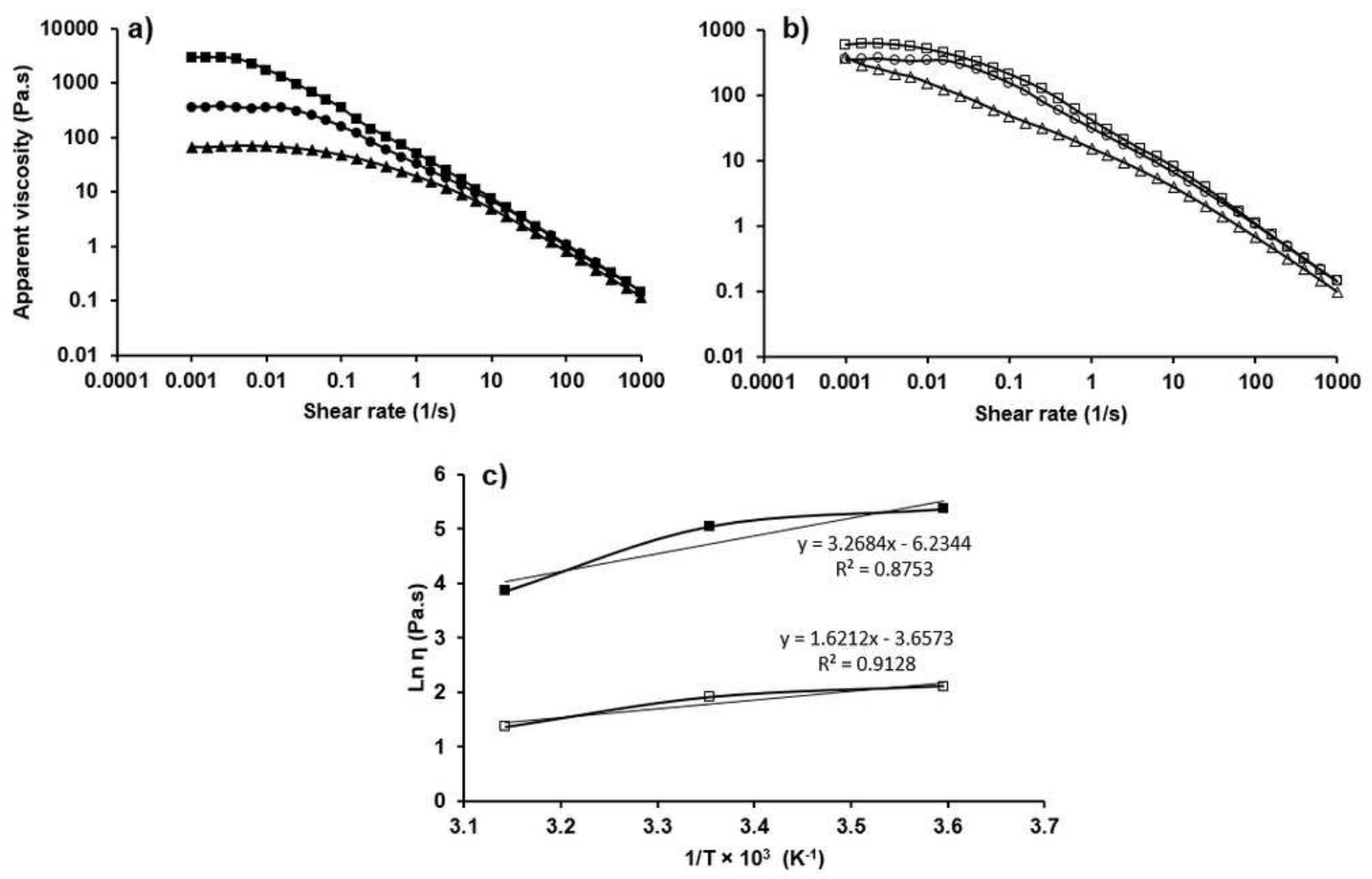

Figure 3. Effect of salts (a; $0 \mathrm{wt} \%(\bullet), 0.2 \mathrm{M} \mathrm{NaCl}(?)$ and $0.2 \mathrm{M} \mathrm{CaCl}_{2}(\square)$ and temperature (b: $5{ }^{\circ} \mathrm{C}(\square), 25^{\circ} \mathrm{C}(\mathrm{O})$ and $45^{\circ} \mathrm{C}(\triangle)$ on the apparent viscosity of $1 \mathrm{wt} \%$ OSP dispersion as a function of shear rate. Arrhenius plots (c) at shear rate of $0.11 / \mathrm{s}(\mathbf{\square})$ and $101 / \mathrm{s}$ (口) for $1 \mathrm{wt} \%$ OSP dispersions.

\section{Figure 3}

See figure for legend. 